\title{
EVALUASI KINERJA SIMPANG TAK BERSINYAL (Studi kasus: Simpang Tiga Jambu Jl.Raya Duri Kosambi)
}

\author{
Tommy Iduwin ${ }^{1}$, Dicki Dian Purnama ${ }^{2}$ \\ ${ }^{1}$ Sekolah Tinggi Teknik PLN - Jakarta \\ ${ }^{2}$ Sekolah Tinggi Teknik PLN - Jakarta \\ E-mail:tommyiduwin@sttpln.ac.id
}

\begin{abstract}
The increasing human need for motorized vehicles has an impact on the number of trips made by humans using motor vehicles will increase. This condition is seen during peak hours, namely during working hours and returning to work so that research is needed to reduce congestion and accidents that occur. Calculation of performance intersection use MKJI 1997. File of this research that got from survey in two times on one day, those are morning and afternoon. The results of the intersection research for the existing conditions produce a degree of saturation (DS) of 1.07. This value exceeds the limit suggested by MKJI 1997 for unsigned intersections (DS <0.75). some alternatives are used to improve the performance of the intersection. Alternative I is an unsignalized intersection by giving a traffic signal and produces $D S=0.92$. Alternative II with geometric widening of road and traffic signal generating value $D S=0.74$ and delay 32.16 det / smp. Level of intersection service is at level $C$ which means stable traffic, travel speed and freedom of movement has been influenced by the large volume of traffic so that the driver can no longer choose the desired speed.
\end{abstract}

Keywords: Performance of unsignalized intersections, MKJI 1997, Degree of saturations, Delay

\begin{abstract}
ABSTRAK
Seiring meningkatnya kebutuhan manusia terhadap kendaraan bermotor berdampak semakin hari jumlah perjalanan yang dilakukan oleh manusia dengan menggunakan kendaraan bermotor akan bertambah banyak. Pada kondisi jam sibuk terlihat bahwa pada pagi hari yang merupakan jam berangkat kantor dan jam sore yang merupakan pulang kerja sehingga perlu dilakukan research untuk mengurangi kemacetan. Manual Kapasitas Jalan Indonesia (MKJI) 1997 digunakan dalam perhitungan kinerja simpang. Data penelitian didapat berupa hasil survey yang dilakukan pagi dan sore pada hari yang sama. Hasil penelitian simpang tiga Jambu Duri Kosambi untuk kondisi eksisting menghasilkan (DS) derajat kejenuhan sebesar 1,07. Batas yang disarankan oleh MKJI 1997 untuk simpang tak bersinyal $(D S<0,75)$ sehingga perlu dilakukan alternatif permasalahan. Alternatif I simpang tak bersinyal dengan memberi sinyal lalu lintas dan menghasilkan DS $=0.92$. Aternatif II dengan pelebaran jalan dan pemberian sinyal lalu lintas menghasilkan nilai DS $=0,74$ dan tundaan $32.16 \mathrm{det} / \mathrm{smp}$. Hasil beberapa alternatif menghasilkan tingkat pelayanan simpang berada pada tingkat $C$ yang artinya artinya lalu lintas stabil, kecepatan perjalanan dan kebebasan bergerak sudah dipengaruhi oleh besarnya volume lalu lintas sehingga pengemudi tidak dapat lagi memilih kecepatan yang diinginkan.
\end{abstract}

Kata kunci: Kinerja Simpang Tak Bersinyal, MKJI 1997, Derajat Kejenuhan, Tundaan. 


\section{PENDAHULUAN}

\subsection{Latar Belakang}

Meningkatnya kebutuhan manusia terhadap kendaraan bermotor berdampak semakin hari jumlah perjalanan yang dilakukan oleh manusia dengan menggunakan kendaraan bermotor akan bertambah banyak. Simpang Jambu adalah simpang dengan tiga lengan yang belum dilengkapi dengan sinyal lampu lalu lintas. Simpang yang terletak di Kota Jakarta Barat, DKI Jakarta ini menghubungkan antara ruas jalan akses Tol Lingkar Luar Jakarta, Tol Jakarta Tangerang, dan akses menuju Stasiun Rawa buaya. Kondisi lingkungan sekitar persimpangan tersebut merupakan daerah padat. Hal ini terlihat dengan adanya perkantoran, pertokoan, akses tol dan akses stasiun. Persimpangan ini adalah persimpangan sebidang tidak bersinyal sehingga tidak ada keteraturan dalam hak jalan. Pola pengaturan lalulintas di persimpangan ini belum teratur sehingga sering ditemukan kendaraan yang berebut ruang untuk melewati persimpangan sehingga mengakibatkan kemacetan dan resiko kecelakaan yang lebih tinggi. Pada jam-jam sibuk pagi hari berupa pada jam masuk kerja dan pagi hari saat pulung kerja sering terjadi kemacetan yang menyebabkan kemacetan berupa antrian panjang sehingga perlu dianalisia dan dicari a;ternatif solusinya.

\subsection{Tinjauan Pustaka}

1. Persimpangan

Menurut Manual Kapasitas Jalan Indonesia (MKJI 1997), ukuran-ukuran yang digunakan untuk memperhitungkan kinerja simpang tak bersinyal berhubungan dengan geometri, lingkungan dan Lalulintas terdiri dari :

1. Kapasitas.

2. Derajat kejenuhan.

3. Tundaan.

4. Peluang antrian.

2. Jenis Simpang

Menurut Alamsyah, A, A (2005) jenis-jenis persimpangan dapat dibedakan antara lain berdasarkan pada hal berikut ini:

1. Persimpangan sebidang

Persimpangan sebidang adalah persimpangan dimana berbagai jalan atau ujung jalan yang masuk ke persimpangan mengarahkan lalu-lintas masuk ke jalur yang berlawanan dengan lalu-lintas lainnya, seperti persimpangan pada jalan-jalan di kota.

2. Persimpangan tak sebidang

Persimpangan tak sebidang adalah persimpangan dimana jalan raya yang menuju ke persimpangan ditempatkan pada ketinggian yang berbeda.

3. Kapasitas Simpang Tak Bersinyal

$\mathrm{C}=\mathrm{CO} \times \mathrm{FW} \times \mathrm{FM} \times \mathrm{FCS} \times \mathrm{FRSU} \times \mathrm{FLT} \times \mathrm{FRT} \times \mathrm{FMI}$

(1)

Dimana :

$\mathrm{C} \quad=$ Kapasitas (smp/jam)

$\mathrm{CO}=$ Kapasitas dasar $(\mathrm{smp} / \mathrm{jam})$

FW = Faktor lebar pendekat

FM $=$ Faktor median jalan utama

FCS $=$ Faktor ukuran kota

FRSU $=$ Faktor hambatan samping dan kendaraan tak bermotor 
FMI $=$ Rasio jalan minor
FRT $=$ Faktor belok kanan
FLT $=$ Faktor belok kiri

$\mathrm{Q} t o t=\mathrm{QA}+\mathrm{QB}+\mathrm{QD}$

4. Derajat Kejenuhan

DS atau singkatan dari derajat kejenuhan merupakan rasio arus lalu lintas (smp/jam) dilambangkan dengan $\mathrm{Q}$ dibagi dengan kapasitas (smp/jam) dilambangkan dengan $\mathrm{C}$ dapat digunakan dengan persamaan berikut:

$D S=\frac{Q t o t}{C}$

keterangan ;

DS $=$ Derajat kejenuhan

C $=$ Kapasitas (smp/jam)

5. Tundaan

a. Tundaan lalu lintas rata-rata untuk seluruh simpang atau disimbolkan dengan (DTi)

DTi $=2+(8.2078 \times$ Ds $)-[(1-D s) \times 2]$

DTi $=\frac{1,0504}{(0,2742-(0,2042 \times \text { Ds })}-(1-$ Ds $\left.) \times 2\right]$

b. Rata-rata tundaan lalu lintas pada jalan utama (DTMA)

DTMA $=1.8+(5.8234 \times$ Ds $)-[(1-D s) \times 1.8]$

$\mathrm{DTi}=\frac{1,05034}{(0,346-(0,2046 \times \mathrm{Ds})}-[(1-\mathrm{Ds}) \times 1,8]$

c. Rata-rata tundaan lalu lintas pada jalan minor (DTMI)

$\mathrm{DTi}=\frac{(\mathrm{Q} t o t x \mathrm{DTi})-(\mathrm{QMAxDTMA})}{\mathrm{QMI}}$

keterangan ;

Qtot $=$ Arus total $(\mathrm{smp} / \mathrm{jam})$,

QMA = Banyaknya kendaraan yang masuk pada simpang memalui jalan major (smp/jam)

QMI = Banyaknya kendaraan yang masuk pada simpang memalui jalan minor (smp/jam)

d. Tundaan geometrik simpang (DG)

Untuk DS $<1,0$ :

$\mathrm{DG}=(1-\mathrm{DS}) \times(\mathrm{PT} \times 6+(1-\mathrm{PT}) \times 3)+\mathrm{DS} \times 4$

6. Tundaan simpang (D)

Tundaan simpang dihitung menggunakan persamaan sebagai berikut :

$\mathrm{D}=\mathrm{DG}+\mathrm{DTI}$ 
7. Peluang Antrian (QP)

Batas atas :

$\mathrm{QPa}=(47,71 \times \mathrm{DS})-(24,68 \times \mathrm{DS} 2)+(56,47 \times \mathrm{DS} 3)$

Batas Bawah :

$\mathrm{QPb}=(9,02 \times \mathrm{DS})+(20,66 \times \mathrm{DS} 2)+(10,49 \times \mathrm{DS} 3)$

\subsection{Tujuan Penelitian}

Adapun tujuan dari penelitian yang dilakukan oleh peneliti adalah :

1. Menganalisis kinerja simpang bersinyal di Simpang Tiga Jambu, Duri Kosambi, Jakarta Barat pada kondisi eksisting.

2. Mengetahui faktor-faktor apa saja yang mempengaruhi kinerja Simpang Tiga Jambu, Duri Kosambi, Jakarta Barat

3. Memberikan alternatif solusi berupa pemecahan masalah yang timbul di Simpang Tiga Jambu, Duri Kosambi, Jakarta Barat

\subsection{Manfaat Penelitian}

Manfaat yang bisa diperoleh dari penelitian ini antara lain adalah :

1. Bisa memperlihatkan kondisi simpang pada kondisi saat ini.

2. Membantu instansi terkait dalam menentukan kebijakan yang berkaitan dengan kinerja simpang.

\section{METODE/PERANCANGAN PENELITIAN}

\subsection{Tahap Pengumpulan Data}

1. Data yang diperlukan

Dimana data yang diperlukan antara lain adalah :

1) Data Primer yang digunakan adalah data hasil survei geometri, data hasil survei volume lalu lintas, dan data hasil survei waktu siklus.

2) Data Sekunder yang digunakan adalah data yang diperoleh dari pihak instansi yang terkait seperti data jumlah pertumbuhan penduduk Provinsi DKI, peta lokasi Provinsi DKI Jakarta dan klasifikasi jalan.

2. Pemilihan Waktu Survei

Pemilihan waktu survei dilakukan pada waktu jam puncak dilokasi Simpang Tiga Jambu Duri Kosambi yaitu pada jam 06.00-09.00 WIB dan sore hari 17.00-20.00 WIB.

3. Peralatan Penelitian

1) Alat Tulis digunakan untuk pencatatan survei.

2) Meteran Roll digunakan untuk pengukuran geomeri.

3) Stop Watch digunakan untuk pencatat waktu tiap interval 15 menit.

4) Jam tangan untuk penunjuk waktu.

5) Kamera digunakan untuk dokumentasi.

6) Surveyor sebagai pengamat dan pencatat arus lalu lintas.

7) Komputer digunakan untuk menganalisis data. 


\subsection{Tahap Analisa}

Ketika semua data-data yang dibutuhkan sudah terkumpul selanjutnya dianalisa. Manual Kapasitas Jalan Indonesia (MKJI) 1997 digunakan dalam perhitungan analisis kinerja simpang. Data penelitian didapat berupa hasil survey yang dilakukan pagi dan sore pada hari yang sama yang selanjutnya dilakukan analisis untuk mengetahui panjang antrian, derajat kejenuhan dan tundaan.

\section{HASIL DAN PEMBAHASAN}

\subsection{Survei Geometri Jalan}

Data yang diperoleh dari pengukuran geometrik pada simpang Jambu Duri Kosambi adalah sebagai berikut :

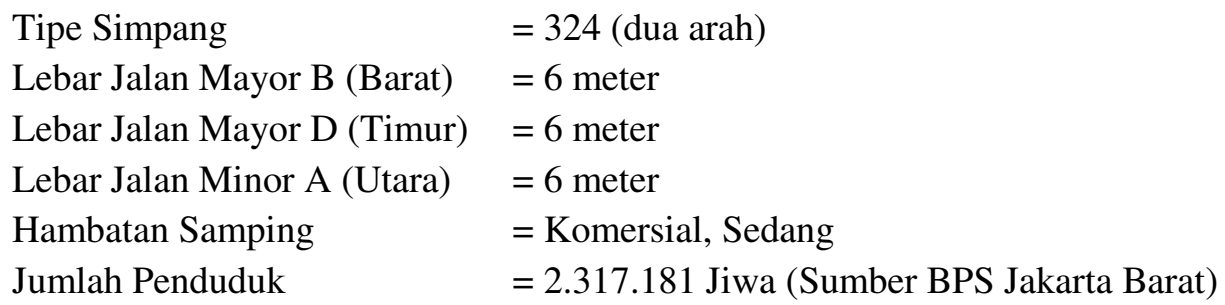

\subsection{Arus Lalu Lintas}

1. Pagi Hari

Tabel 1 Rekapitulasi Arus Lalu-Lintas Pagi Hari

\begin{tabular}{|c|c|c|c|c|c|c|c|c|c|c|c|c|c|c|c|c|c|c|c|c|c|c|c|c|c|c|}
\hline \multirow{3}{*}{ No } & \multirow{3}{*}{$\begin{array}{c}\text { Waktu } \\
(06.00 \\
09.00) \\
\end{array}$} & & \multicolumn{6}{|c|}{ Dari Jl. Duri Kosambi (GITC) } & \multirow{3}{*}{\multicolumn{2}{|c|}{\begin{tabular}{|c|c|} 
No & $\begin{array}{c}\text { Waktu } \\
(06.00- \\
09.00)\end{array}$ \\
\end{tabular}}} & & \multicolumn{6}{|c|}{ Jl. Pondok Randu } & \multirow{3}{*}{\multicolumn{2}{|c|}{\begin{tabular}{|c|c|} 
No & $\begin{array}{c}\text { Waktu } \\
(06.00- \\
09.00)\end{array}$ \\
\end{tabular}}} & & \multicolumn{6}{|c|}{ JL. Duri Kosambi (Kresek) } \\
\hline & & & \multicolumn{3}{|c|}{ Pondok Randu } & \multicolumn{3}{|c|}{ Kresek } & & & & \multicolumn{3}{|c|}{ GITC } & \multicolumn{3}{|c|}{ Kresek } & & & & \multicolumn{3}{|c|}{ Pondok Randu } & \multicolumn{3}{|c|}{ GITC } \\
\hline & & & LV & $\mathrm{HV}$ & $\mathrm{MC}$ & LV & $\mathrm{HV}$ & $\mathrm{MC}$ & & & & LV & $\mathrm{HV}$ & $\mathrm{MC}$ & LV & $\mathrm{HV}$ & $\mathrm{MC}$ & & & & LV & $\mathrm{HV}$ & $\mathrm{MC}$ & LV & HV & $\mathrm{MC}$ \\
\hline \multirow[t]{2}{*}{1} & \multirow{2}{*}{$\begin{array}{r}06.00- \\
07.00\end{array}$} & $\begin{array}{c}\text { Kendara } \\
\text { an }\end{array}$ & 32 & 1 & 81 & 98 & 3 & 362 & \multirow[t]{2}{*}{1} & \multirow{2}{*}{$\begin{array}{c}06.00- \\
07.00\end{array}$} & $\begin{array}{c}\text { Kendar } \\
\text { aan }\end{array}$ & 19 & 0 & 56 & 43 & 3 & 130 & \multirow{2}{*}{1} & \multirow{2}{*}{\begin{tabular}{|c|}
$06.00-$ \\
07.00
\end{tabular}} & $\begin{array}{c}\text { Kenda } \\
\text { raan }\end{array}$ & 472 & 15 & 1431 & 83 & 6 & 362 \\
\hline & & smp & 32 & 1.3 & 40.5 & 98 & 3.9 & 181 & & & smp & 19 & 0 & 28 & 43 & 3.9 & 65 & & & smp & 472 & 19.5 & 715.5 & 83 & 7.8 & 181 \\
\hline & \multicolumn{2}{|c|}{ Total (smp) } & \multicolumn{3}{|c|}{73.8} & \multicolumn{3}{|c|}{282.9} & & \multicolumn{2}{|c|}{ Total (smp) } & \multicolumn{3}{|c|}{47} & \multicolumn{3}{|c|}{111.9} & & \multicolumn{2}{|c|}{ Total (smp) } & \multicolumn{3}{|c|}{1207} & \multicolumn{3}{|c|}{271.8} \\
\hline & Total Q & A (smp) & & & & & & & & Total QB & B (smp) & & & 15 & 8.9 & & & & Total QC & $=(\mathrm{smp})$ & & & & & & \\
\hline 2 & $07.00-$ & $\begin{array}{c}\text { Kendara } \\
\text { an }\end{array}$ & 66 & 1 & 181 & 323 & 16 & 692 & 2 & $07.00-$ & endaraa & 36 & 2 & 91 & 49 & 3 & 252 & 2 & 07.00 & $\begin{array}{c}\text { Kenda } \\
\text { raan }\end{array}$ & 521 & 18 & 2143 & 92 & 5 & 402 \\
\hline & 08.00 & smp & 66 & 1.3 & 90.5 & 323 & 20.8 & 346 & & & smp & 36 & 2.6 & 46 & 49 & 3.9 & 126 & & 08.00 & smp & 521 & 23.4 & 1072 & 92 & 6.5 & 201 \\
\hline & To & tal & & 157.8 & & & 689.8 & & & Total ( & (smp) & & 84.1 & & & 178.9 & & & Total ( & smp) & & 1615.9 & & & 299.5 & \\
\hline & Total Q & $A(s m p)$ & & & & & & & & Total QB & B (smp) & & & 26 & & & & & Total QC & $=(\mathrm{smp})$ & & & & & & \\
\hline 3 & $08.00-$ & $\begin{array}{c}\text { Kendara } \\
\text { an }\end{array}$ & 63 & 1 & 242 & 96 & 25 & 785 & 3 & 08.00- & endaraa & 32 & 1 & 140 & 110 & 19 & 348 & 3 & 08.00- & $\begin{array}{c}\text { Kenda } \\
\text { raan }\end{array}$ & 421 & 55 & 1695 & 74 & 5 & 454 \\
\hline & 09.00 & smp & 63 & 1.3 & 121 & 96 & 32.5 & 392.5 & & & smp & 32 & 1.3 & 70 & 110 & 25 & 174 & & & smp & 421 & 71.5 & 847.5 & 74 & 6.5 & 227 \\
\hline & & tal & & 185.3 & & & 521 & & & Total ( & (smp) & & 103.3 & & & 308.7 & & & Total ( & smp) & & 1340 & & & 307.5 & \\
\hline & Total Q & $A(s m p)$ & & & & & & & & Total QB & B (smp) & & & 41 & & & & & Total QC & $(\mathrm{smp})$ & & & & & & \\
\hline
\end{tabular}

Sumber : Hasil Analisis

Dari Tabel 1 diatas didapatkan hasil data $\mathrm{Q}_{\text {тот }}$ untuk pagi hari didapat $\mathrm{Q}_{\mathrm{A}}, \mathrm{Q}_{\mathrm{B}}$ dan $\mathrm{Q}_{\mathrm{C}}$ yang dijumlahkan menjadi Qtot. Nilai Qtot diambil dari data $Q_{A}, Q_{B}$ dan $Q_{C}$ yang memiliki nilai terbesar untuk jam pagi hari

$$
\begin{aligned}
\text { Qtot } & =\mathrm{Q}_{\mathrm{B}}+\mathrm{Q}_{\mathrm{A}}+\mathrm{Q}_{\mathrm{D}} \\
& =848+412+1915=3175 \mathrm{smp} / \mathrm{jam}
\end{aligned}
$$




\section{Sore Hari}

Tabel 2 Rekapitulasi Arus Lalu-Lintas Pagi Hari

\begin{tabular}{|c|c|c|c|c|c|c|c|c|c|c|c|c|c|c|c|c|c|c|c|c|c|c|c|c|c|c|}
\hline \multirow{3}{*}{ No } & \multirow{3}{*}{\begin{tabular}{|c|} 
Waktu \\
$(17.00-$ \\
$20.00)$ \\
\end{tabular}} & & \multicolumn{6}{|c|}{ Dari Jl. Duri Kosambi (GITC) } & \multirow{3}{*}{\multicolumn{2}{|c|}{\begin{tabular}{c|c} 
No & $\begin{array}{c}\text { Waktu } \\
(17.00- \\
20.00)\end{array}$ \\
\end{tabular}}} & & \multicolumn{6}{|c|}{ Jl. Pondok Randu } & \multirow{3}{*}{\multicolumn{2}{|c|}{ No $\begin{array}{c}\text { Waktu } \\
(17.00- \\
20.00) \\
\end{array}$}} & & \multicolumn{6}{|c|}{ JL. Duri Kosambi (Kresek) } \\
\hline & & & \multicolumn{3}{|c|}{ Pondok Randu } & \multicolumn{3}{|c|}{ Kresek } & & & & \multicolumn{3}{|c|}{ GITC } & \multicolumn{3}{|c|}{ Kresek } & & & & \multicolumn{3}{|c|}{ Pondok Randu } & \multicolumn{3}{|c|}{ GITC } \\
\hline & & & LV & $\mathrm{HV}$ & $\mathrm{MC}$ & $\mathrm{LV}$ & $\mathrm{HV}$ & MC & & & & LV & $\mathrm{HV}$ & $\mathrm{MC}$ & LV & $\mathrm{HV}$ & $\mathrm{MC}$ & & & & $\mathrm{LV}$ & $\mathrm{HV}$ & $\mathrm{MC}$ & LV & $\mathrm{HV}$ & $\mathrm{MC}$ \\
\hline \multirow[t]{2}{*}{1} & \multirow[t]{2}{*}{$7.00-18.0$} & $\begin{array}{c}\text { Kendara } \\
\text { an } \\
\end{array}$ & 56 & 1 & 244 & 124 & 18 & 1165 & \multirow[t]{2}{*}{1} & \multirow[t]{2}{*}{$7.00-18.0$} & $\begin{array}{c}\text { Kendar } \\
\text { aan }\end{array}$ & 50 & 0 & 132 & 271 & 22 & 473 & \multirow[t]{2}{*}{1} & \multirow[t]{2}{*}{$7.00-18.0$} & $\begin{array}{c}\begin{array}{c}\text { Kenda } \\
\text { raan }\end{array} \\
\end{array}$ & 238 & 19 & 1128 & 83 & 8 & 583 \\
\hline & & smp & 56 & 1.3 & 122 & 124 & 23.4 & 582.5 & & & smp & 50 & 0 & 66 & 271 & 29 & 237 & & & smp & 238 & 24.7 & 564 & 83 & 10.4 & 291.5 \\
\hline & \multicolumn{2}{|c|}{ Total (smp) } & \multicolumn{3}{|c|}{179.3} & \multicolumn{3}{|c|}{729.9} & \multicolumn{3}{|c|}{ Total (smp) } & \multicolumn{3}{|c|}{116} & \multicolumn{3}{|c|}{536.1} & \multicolumn{3}{|c|}{ Total (smp) } & \multicolumn{3}{|c|}{826.7} & & 384.9 & \\
\hline & Total QA & A (smp) & & & & & & & & Total QB & $B(\mathrm{smp})$ & & & & 2.1 & & & & Total QC & $C(\mathrm{smp})$ & & & 121 & & & \\
\hline 2 & $8.00-19.0$ & $\begin{array}{c}\text { Kendara } \\
\text { an }\end{array}$ & 40 & 0 & 169 & 112 & 9 & 1022 & 2 & $8.00-19.0$ & $\begin{array}{c}\text { Kendar } \\
\text { aan }\end{array}$ & 51 & 1 & 143 & 349 & 18 & 434 & 2 & $8.00-19.0$ & $\begin{array}{c}\text { Kenda } \\
\text { raan }\end{array}$ & 220 & 18 & 904 & 69 & 5 & 568 \\
\hline & & smp & 40 & 0 & 84.5 & 112 & 11.7 & 511 & & & smp & 51 & 1.3 & 72 & 349 & 23 & 217 & & & smp & 220 & 23.4 & 452 & 69 & 6.5 & 284 \\
\hline & Total ( & (smp) & & 124.5 & & & 634.7 & & & Total ( & (smp) & & 123.8 & & & 589.4 & & & Total ( & (smp) & & 695.4 & & & 359.5 & \\
\hline & Total QA & A (smp) & & & & & & & & Total Q & B (smp) & & & & 13.2 & & & & Total QC & $C(\mathrm{smp})$ & & & 105 & & & \\
\hline 3 & $9.00-20.0$ & $\begin{array}{c}\text { Kendara } \\
\text { an }\end{array}$ & 44 & 0 & 159 & 123 & 9 & 1127 & 3 & $9.00-20.0$ & $\begin{array}{c}\begin{array}{c}\text { Kendar } \\
\text { aan }\end{array} \\
\end{array}$ & 51 & 0 & 138 & 322 & 6 & 340 & 3 & $9.00-20.0$ & $\begin{array}{c}\begin{array}{c}\text { Kenda } \\
\text { raan }\end{array} \\
\end{array}$ & 192 & 8 & 659 & 52 & 6 & 807 \\
\hline & & smp & 44 & 0 & 79.5 & 123 & 11.7 & 563.5 & & & smp & 51 & 0 & 69 & 322 & 7.8 & 170 & & & smp & 192 & 10.4 & 329.5 & 52 & 7.8 & 403.5 \\
\hline & Total ( & (smp) & & 123.5 & & & 698.2 & & & Total ( & (smp) & & 120 & & & 499.8 & & & Total & (smp) & & 531.9 & & & 463.3 & \\
\hline & Total QA & A (smp) & & & & & & & & Total QE & B (smp) & & & & 9.8 & & & & Total QC & $C(\mathrm{smp})$ & & & 99 & & & \\
\hline
\end{tabular}

Sumber : Hasil Analisis

Dari Tabel 2 diatas didapatkan hasil data $\mathrm{Q}_{\text {тот }}$ untuk pagi hari didapat $\mathrm{Q}_{\mathrm{A}}, \mathrm{Q}_{\mathrm{B}}$ dan $\mathrm{Q}_{\mathrm{C}}$ yang dijumlahkan menjadi Qtot. Nilai Qtot diambil dari data $Q_{A}, Q_{B}$ dan $Q_{C}$ yang memiliki nilai terbesar untuk jam sore hingga malam hari

$$
\begin{aligned}
\text { Qtot } & =\mathrm{Q}_{\mathrm{B}}+\mathrm{Q}_{\mathrm{A}}+\mathrm{Q}_{\mathrm{D}} \\
& =909+713+1212=2834 \mathrm{smp} / \mathrm{jam}
\end{aligned}
$$

\subsection{Analisa Simpang}

Hasil perhitungan analisis simpang tiga Jambu Duri Kosambi, didapatkan nilai derajat kejenuhan paling besar adalah pada waktu sore hingga malam hari yaitu dengan derajat kejenuhan sebesar 1,07 dan Panjang antrian batas atas dan bawah sebesar 46.16 - 91.97. Dengan diperoleh derajat kejenuhan sebesar 1,07 yang artinya simpang tersebutmemiliki tundaan yang tak terhingga. Sehingga tingkat pelayanan simpang ini termasuk F yang artinya Arus lalu lintas tertahan pada kecepatan rendah, sering kali terjadi kemacetan dan arus lalu lintas rendah.

Tabel 3 Perbandingan Kinerja Simpang Tiga Jambu

\begin{tabular}{|c|c|c|c|c|c|}
\hline Waktu & $\begin{array}{c}\text { Arus Total } \\
(\text { smp/jam) }\end{array}$ & $\begin{array}{c}\text { Kapasitas } \\
(\text { smp/jam) }\end{array}$ & DS & $\begin{array}{c}\text { D } \\
\text { (det/smp) }\end{array}$ & QP (\%) \\
\hline $06.00-09.00$ & 3175 & 4053 & 0.8 & 13.21 & $25.81-51.29$ \\
\hline $17.00-20.00$ & 2834 & 2640 & 1.07 & 18 & $46.16-91.97$ \\
\hline
\end{tabular}

Sumber : Hasil Analisis

\subsection{Alternatif Solusi}

1. Pemberian Sinyal Lalu Lintas

Pemberian sinyal lalu lintas cukup berpengaruh untuk mengurangi nilai derajat kejenuhan dan nilai tundaan. Nilai derajat kejenuhan yang didapat pada simpang menjadi 0.92. Sedangkan nilai tundaan lalu lintas Simpang Tiga Jambu menjadi 51.24 detik/smp yang artinya masih diatas standar acuan 
MKJI yaitu 0.75 sehingga masih perlu dilakukan alternatif lain untuk mengurangi tundaan dan derajat kejenuhan.

Tabel 4 Penentuan Waktu Sinyal

\begin{tabular}{|c|c|c|c|c|c|}
\hline Arus & Rasio & Rasio & Waktu & Kapa- & Derajat \\
\hline lalu & Arus & fase & hijau & sitas & jenuh \\
\hline lintas & $F R=$ & $P R=$ & det & smp/j & \\
\hline \multirow[t]{2}{*}{$\mathrm{smp} / \mathrm{j}$} & & & & $C=$ & DS= \\
\hline & & $\mathrm{FR}_{\mathrm{CRII}}$ & & & \\
\hline $\mathbf{Q}$ & $Q / S$ & IFR & g & Sxg/c & $Q / C$ \\
\hline (18) & (19) & (20) & (21) & (22) & (23) \\
\hline 696 & 0.195 & 0.233 & 32 & 760 & 0.9154 \\
\hline 768 & 0.215 & 0.257 & 35 & 839 & 0.9154 \\
\hline 1041 & 0.291 & 0.348 & 47 & 1137 & 0.9154 \\
\hline
\end{tabular}

Sumber : Hasil Analisis

2. Pelebaran Jalan dan Pemberian Sinyal Lalu Lintas

Tabel 5 Hasil Perhitungan DS setelah pelebaran jalan

\begin{tabular}{|c|c|c|c|c|c|}
\hline Arus & Rasio & Rasio & Waktu & Kapa- & Derajat \\
\hline lalu & Arus & fase & hijau & sitas & jenuh \\
\hline lintas & $\mathrm{FR}=$ & $P R=$ & det & smp/j & \\
\hline \multirow[t]{2}{*}{ smp/j } & & & & $C=$ & $\mathrm{DS}=$ \\
\hline & & $F^{F R_{C H I}}$ & & & \\
\hline $\mathbf{Q}$ & $Q / S$ & $\underline{I F R}$ & g & Sxg/c & $Q / C$ \\
\hline (18) & (19) & (20) & (21) & (22) & (23) \\
\hline 696 & 0.130 & 0.228 & 10 & 944 & 0.7370 \\
\hline 768 & 0.129 & 0.227 & 10 & 1042 & 0.7370 \\
\hline 1041 & 0.175 & 0.307 & 13 & 1412 & 0.7370 \\
\hline
\end{tabular}

Sumber : Hasil Analisis

Pelebaran Jalan dan pemberian sinyal lau lintas sangat berpengaruh untuk mengurangi nilai derajat kejenuhan yang terjadi. Nilai DS dan D pada simpang tiga jambu menjadi 0.74 yang sebelumnya 0.92 . Nilai 0.74 sudah memenuhi standar dari MKJI yaitu kurang dari sama dengan 0.75. 


\section{Rekapitulasi Alternatif Solusi}

Pada Table 6 dapat dilihat bahwa pada saat diberikan alternatif 1 yaitu pemberian sinyal lalu lintas nilai derajat kejenuhan turun dari 1.07 menjadi 0.92. Akan tetapi masih dalam Level of service (LOS) tipe D yang artinya arus lalu lintas masih belum stabil. Sedangkan Pada saat diberikan alternatif 2 yaitu pelebaran jalan mayor minor dan pemberian sinyal lalu lintas nilai drajat kejenuhan turun lagi hingga 0.74. Hal ini memberikan nilai level of service (LOS) pada lalu lintas tersebut menjadi tipe C yang artinya lalu lintas masih stabil, kecepatan perjalanan dan kebebasan bergerak sudah dipengaruhi oleh besarnya volume lalu lintas sehingga pengemudi tidak dapat lagi memilih kecepatan yang diinginkannya.

Tabel 6 Rekapitulasi Alternatif Kinerja Simpang

\begin{tabular}{|c|c|c|c|c|}
\hline Data & Kapasitas & $\begin{array}{c}\text { Derajat } \\
\text { Kejenuhan }\end{array}$ & Tundaan & $\begin{array}{c}\text { Level Of } \\
\text { Service }\end{array}$ \\
\hline Eksisting & 2640 & 1.07 & 18 & $\mathrm{~F}$ \\
\hline \multicolumn{5}{|c|}{ Alternatif 1 } \\
\hline Pendekat Utara & 760 & 0.92 & 51.24 & D \\
\hline Pendekat Barat & 839 & 0.92 & 51.24 & D \\
\hline Pendekat Timur & 1137 & 0.92 & 51.24 & D \\
\hline \multicolumn{5}{|c|}{ Alternatif 2 } \\
\hline Pendekat Utara & 944 & 0.74 & 33.16 & $\mathrm{C}$ \\
\hline Pendekat Barat & 1042 & 0.74 & 33.16 & $\mathrm{C}$ \\
\hline Pendekat Timur & 1412 & 0.74 & 33.16 & $\mathrm{C}$ \\
\hline
\end{tabular}

Sumber : Hasil Analisis

\section{KESIMPULAN DAN SARAN}

Kesimpulan pada penelitian ini adalah kinerja simpang tiga Jambu Duri Kosambi untuk kondisi simpang tak bersinyal pada keadaan eksisting menghasilkan derajat kejenuhan (DS) $=1,07$ dan peluang antrian antara 46\%-92\%. Alternatif solusi digunakan untuk mengurangi nilai derajat kejenuhan dan tundaan, alternatif 1 adalah dengan memberikan sinyal lalu lintas pada simpang di tiap jalan baik berupa jalan mayor maupun jalan minor. Hasil dari alternatif 1 adalah didapatkan nilai derajat kejenuhan sebesar 0,92 . Alternatif 1 ini memberikan sedikit pengaruhnya dalam mengurangi derajat kejenuhan (DS) yaitu sebesar 0,92. Untuk nilai tundaan berkurang sebesar $51.24 \mathrm{det} / \mathrm{smp}$. Tingkat pelayanan simpang (level of service) tiga dengan hasil tersebut dari F menjadi D. Alternatif solusi kedua yaitu pelebaran jalan mayor minor dan diberikan sinyal lalu lintas didapat derajat kejenuhan sebesar 0,74 dengan tundaan rata-rata sebesar $33.14 \mathrm{det} / \mathrm{smp}$. Pada alternatif solusi kedua tingkat pelayanan simpang (level of service) menjadi $\mathrm{C}$ dikarenakan derajat kejenuhan sudah diangka $<0.75$. Alternatif yang terbaik adalah alternatif 2 karena memiliki nilai DS dan antrian paling rendah tetapi untuk implementasinya membutuhkan cost yang tinggi. Saran dalam penelitian ini adalah sebaiknya memperhitungkan pertumbuhan jumlah kendaraan dalam beberapa tahun kedepan , memperhitungkan alternatif lain yang lebih optimal sehingga dapat meningkatkan kinerja simpang dan kepada pihak terkait seperti dishub, LLAJ dan Polantas dapat melakukan rekayasa lalu lintas pada jam sibuk yaitu pada Simpang Tiga Jambu jam puncaknya pada pagi dan sore hari. 


\section{DAFTAR PUSTAKA}

[1] Alamsyah, A., (2005), Rekayasa Lalulintas, Universitas Muhammadiyah Malang, Malang

[2] Abubakar, I., (1995). Menuju Lalu Lintas dan Angkutan Jalan Yang Tertib, Departemen Pekerjaan Umum Direktorat Jendral Bina Marga, Jakarta

[3] Departemen Permukiman dan Prasarana Wilayah, 2004, Perencanaan Bundaran untuk Persimpangan Sebidang. Pd T-20-2004-B.

[4] Direktorat BSLLAK, 1999, Pedoman Perencanaan dan Pengoperasian Lalu Lintas di Wilayah Perkotaan, Jakarta

[5] Direktorat Jendral Bana Marga, 1997, Manual Kapasitas Jalan Indonesia (MKJI), Jakarta.

[6] Tamin, Ofyar Z, . 1997, Perencanaan Dan Permodelan Transportasi. ITB, Bandung. 